\title{
A plea for a unified approach to sedation in gastrointestinal endoscopy in Romania: results from a prospective multicentric trial
}

\author{
THEODOR VOIOSU ${ }^{1,2}$, TUDOR MOGA ${ }^{3}$, CRISTIAN NEDELCU $^{4}$, CRISTINA TOCIA $^{5,6}$, MONICA STATE $^{1}$, \\ CLAUDIA PUSCASU ${ }^{1}$, ANDREEA BENGUS ${ }^{1}$, ANDREI VOIOSU ${ }^{1,2}$, LUCIAN NEGREANU ${ }^{7}$, EUGEN DUMITRU ${ }^{5,6}$, \\ GABRIEL CONSTANTINESCU ${ }^{2,4}$, BOGDAN MATEESCU $^{1,2}$, IOAN SPOREA $^{3}$ \\ ${ }^{1}$ Gastroenterology Department, Colentina Clinical Hospital, Bucharest, Romania \\ ${ }^{2}$ Internal Medicine Department, "Carol Davila” School Of Medicine, Bucharest, Romania \\ ${ }^{3}$ Department of Gastroenterology and Hepatology, "Victor Babeș" University of Medicine and Pharmacy, Timișoara, Romania \\ ${ }^{4}$ Gastroenterology Department, Floreasca Emergency Hospital, Bucharest, Romania \\ ${ }^{5}$ Department of Gastroenterology, County Clinical Emergency Hospital of Constanta, Romania \\ ${ }^{6}$ Faculty of General Medicine, Ovidius University, Constanta, Romania \\ ${ }^{7}$ Gastroenterology Department, Emergency University Hospital, Bucharest, Romania
}

\begin{abstract}
Background. Adequate sedation is a prerequisite for quality endoscopic examination of the digestive tract. We aimed to evaluate the current practices and safety profile of sedation for gastrointestinal endoscopy in Romania and its impact on the technical success of the procedure and procedure-related adverse events.

Methods. We conducted a prospective, multicentric, observational study including all patients undergoing digestive endoscopic procedures under various degrees of sedation. We collected data regarding the endoscopic procedure, type and degree of sedation, drug regimens, personnel in charge of sedation, and relevant patient related information. The main study outcome was the rate of sedation-related adverse events; secondary study outcomes included procedure-related adverse events and the impact of sedation on procedure success.

Results. 1,043 consecutive endoscopic procedures from eight Romanian endoscopy units were included in our study. Sedation regimens were highly variable between participating centers, with $566(54 \%)$ of procedures being performed under sedation provided by an anaesthesiologist. Sedation-related adverse events occurred in 40 cases $(3.8 \%)$, most of them were mild respiratory and cardiovascular events and all reversed spontaneously.

On multivariate analysis, male gender, procedure type (endoscopic ultrasound and endoscopic retrograde cholangiopancreatography) and deep sedation were risk factors for complications. The endoscopy unit, ASA status, age and type of sedative did not influence the complication rate.

Conclusion. In conclusion, sedation for endoscopic procedures is generally safe, despite a high variability in sedation practices between centers in Romania. Establishing a national guideline on sedation for gastrointestinal endoscopy will ensure consistent and safe practice for these procedures.
\end{abstract}

Key words: anesthesiologist, complications, endoscopy, sedation, gastroenterologist, guidelines.

\begin{abstract}
What is important?
Despite the clear benefit of sedation in digestive endoscopy, practices in Romania are highly heterogeneous as healthcare professionals' participation in this process is not clearly regulated by local authorities. In our study we demonstrated that sedation in gastrointestinal(GI) endoscopy is generally safe, regardless of the personnel administering sedation but developing and implementing national guidelines for sedation during GI endoscopy is a necessity if we aim to improve the quality of patient care in the endoscopy suite.
\end{abstract}

\section{INTRODUCTION}

The scope and use of endoscopic procedures has greatly expanded over the past decades and sedation has been increasingly used to ensure a high quality examination while maximizing the comfort of both patient and endoscopist [1].
Sedation comprises a continuum of states ranging from minimal sedation (anxiolysis), through general anesthesia [2]. Although the use of sedatives for GI procedures is highly variable, and is influenced by many factors such as differences in regulation of drug use and 
administration, reimbursement, cultural factors (including patient and physician preference) and resource availability (including access to anesthesiologist administered sedation), there has been an attempt to set standards of practice via national and international guidelines [2,3].

Achieving a safe and effective level of sedation during endoscopic procedures requires careful consideration for the patient and adequate tailoring of drug regimes. Despite the clear benefit of sedation in digestive endoscopy, practices in Romania are highly heterogeneous as healthcare professionals' participation in this process is not clearly regulated by local authorities. In addition to this, there seem to be significant differences among centers $[4,5]$ regarding the types and dosages of drugs, used as well as protocols for patient monitoring during and after sedation.

We aimed to evaluate the current status of sedation practices, the type of drug regimens administered and the impact of these factors on patient safety and procedure outcome in Romania.

\section{MATERIAL AND METHODS}

\section{Study design}

We conducted a prospective, observational, multicenter study that included all patients undergoing endoscopic procedures involving different levels of sedation. We invited gastrointestinal endoscopists from eight medical centers ( 5 public hospitals, 3 private practices endoscopy centers) in 3 regions of Romania to participate in our study. In order to capture data regarding preferences in different institutions, we included high and low-volume endoscopy centers $(>1,000$ and $<1,000$ procedures per year respectively), from both the public and the private sector, in a catchment area with a population of over 3 million.

Consecutive endoscopic procedures requiring sedation in the participating centers, were included in this study. All patients signed a standard consent form prior to the endoscopic procedure in which the main risks of both the procedure and sedation medication were listed and explained. Patients requiring deep sedation with or without orotracheal intubation signed an explicit anaesthesia consent form.

Sedation regimens. In the absence of national guidelines regarding sedation in gastrointestinal endoscopy, the sedation regimen was decided by the attending physician at each study centre, on a case- by-case basis, and in accordance institutional regulations, including the available facilities and on-site medical staff. For high risk patients, as defined by the European Society of Anaesthesiology (ESA) and the European Board of Anaesthesiology [6], as well as for extensive endoscopic procedures, the sedation regimen was discussed in a multidisciplinary team consisting of the leading endoscopist, anaesthesiologist and anaesthesiologynurse and sedation was provided by anaesthesiology personnel, where available. In cases with non-anaesthesiology guided sedation, the attending gastroenterologist, a second gastroenterologist or a nurse with experience in sedation were responsible for deciding the doses and sedation regimen.

Patients undergoing endoscopic procedures received intravenous sedation (moderate or deep sedation) or general anaesthesia. Moderate sedation (conscious sedation) was defined as maintaining a purposeful response to verbal or tactile stimuli and normal cardiovascular and respiratory functions, deep sedation was defined as a state of depressed consciousness from which the patient cannot be easily aroused but still responds to painful stimulation, and general anaesthesia implied unresponsiveness to painful stimuli [7].

All patients were closely monitored in the ward or recovery room, as per local protocol, for a minimum of 30 minutes for procedures done in an ambulatory setting and on a case-by-case basis for patients admitted into the hospital. In case of procedure or sedation-related complications, the patient received further medical care as required.

Data collection. We used a standard form completed by the attending endoscopist in order to collect data regarding the endoscopic procedure, medication used for sedation, medical personnel in charge of sedation, and patient-related information. Data about the endoscopic procedure included procedure type [esophagogastroduodenoscopy, colonoscopy, endoscopic ultrasound (EUS), endoscopic retrograde cholangiopancreatgraphy (ERCP), enteroscopy], setting (elective vs. emergency procedure) and purpose (diagnostic vs. therapeutic procedure). For each patient we recorded demographic data, American Society of Anesthesiologists (ASA) physical status classification scores (Annex 1), and relevant coexisting medical conditions (i.e. cardiac, pulmonary, hepatic, renal failure, advanced cancer etc.). The attending endoscopist was also required to assess the impact of sedation on the procedure itself (adequate sedation, 
insufficient sedation that impeded the endoscopic procedure and inadequate sedation that required discontinuation of the procedure) and document all endoscopy and anaesthesia-related complications up to the discharge of the patient. When the goal of the procedure (ie intubation of the caecum and adequate bowel inspection in screening colonoscopy, resection of target lesions, stent placement etc) was fulfilled, the attended endoscopist graded this procedure as technically successful; in all other cases where the clinical indication was not met, either because of inadequate sedation or because of endoscopyrelated issues, the procedure was deemed a technical failure. Complications were graded as: mild (spontaneously reversible, i.e minor bleeding, transient hypoxemia, drop in blood pressure $<25 \%$ ), moderate (need for antagonist medication and/or non-invasive ventilation, i.e drop in blood pressure $>25 \%$, persistent bradycardia or tachycardia, etc) and severe (requiring orotracheal intubation and/or admittance in an intensive-care unit, i.e perforation, aspiration, major cardiac or respiratory events).
Statistical analysis. Statistical analysis was performed using IBM SPSS version 20.0 for Windows (IBM Corp, Armonk NY, USA). Data analysis included descriptive statistics computed for continuous variables, expressed as mean and standard deviation (SD). Categorical variables were described as counts and percentages and analysed by the Chi-Square test. Univariate analysis was conducted to assess the impact of procedure and patient-related factors on sedation-related complications. We conducted multivariable analysis, including in the model all variables of potentially clinical relevance (age, gender, ASA status, type and setting of procedure, sedation regimen and participating center) to determine risk factors for anesthesia-related adverse events. Variables with $>10 \%$ missing data were excluded from the statistical analysis models. A p-value $<0.05$ was considered statistically significant.

Ethical considerations. The study was approved by the local ethical committee at the participating centers, and was conducted according to the principles of the declaration of Helsinki.

\section{Annex 1}

American Society for Anaesthesiology (ASA) physical status classification

\begin{tabular}{|l|l|}
\hline Class & Description \\
\hline ASA I & The patient is normal and healthy \\
\hline ASA II & $\begin{array}{l}\text { The patient has mild systemic disease that does not limit their activities (eg, controlled hypertension } \\
\text { or controlled diabetes without systemic sequelae) }\end{array}$ \\
\hline ASA III & $\begin{array}{l}\text { The patient has moderate or severe systemic disease, which does limit their activities (e.g. stable angina } \\
\text { or diabetes with systemic sequelae) }\end{array}$ \\
\hline ASA IV & $\begin{array}{l}\text { The patient has severe systemic disease that is a constant potential threat to life (eg, severe congestive heart } \\
\text { failure, end-stage renal failure) }\end{array}$ \\
\hline ASA V & The patient is morbid and is at substantial risk of death within 24 hours (with or without a procedure) \\
\hline
\end{tabular}

\section{RESULTS}

A total of 1,043 consecutive endoscopic procedures requiring sedation, performed by 16 attending endoscopists and their trainees (where applicable), were included in the study between August 2019 and December 2019 at the 8 participating centers. Most procedures were performed in public hospitals $(\mathrm{n}=911,87.3 \%)$ and only $132(12.7 \%)$ procedures in a private practice setting.

The mean age of the patients was $61( \pm 14)$ years and $515(49 \%)$ had at least one coexisting medical condition. Colonoscopy was the most frequent procedure in our cohort $(429,41.1 \%)$, followed by ERCP $(329,31.5 \%)$. Details on characteristics of the patient population and procedures are presented in Tables 1 and 2 .

Almost half of the documented procedures were therapeutic $(45 \%)$ and the vast majority were elective procedures (92.5\%). 211(20.2\%) of the endoscopic procedures, had no clear indication provided by the attending endoscopist on their final report. In 566 (54.3\%) cases, sedation was provided by the anaesthesiologist, while in the rest of the cases the attending endoscopist was responsible for sedation. Anesthesiologist-administered sedation was more frequently provided for therapeutic procedures, compared to diagnostic procedures $(312 / 469$ vs 255/363, $p=0.003$, Chi-Square test). 
Table 1

Patient population data

\begin{tabular}{|l|l|}
\hline GENDER, male/female, $\mathbf{n}(\boldsymbol{\%})$ & $493(47.3) / 488(46.8)$ \\
\hline Age, mean (SD), years & $61(14)$ \\
\hline $\begin{array}{l}\text { Coexisting medical conditions, } \mathbf{n} \\
(\boldsymbol{)})\end{array}$ & $515(49.4)$ \\
\hline Cardiovascular & $42(4)$ \\
\hline Pulmonary & $24(2.3)$ \\
\hline Renal & $44(4.2)$ \\
\hline Hepatic & $50(4.8)$ \\
\hline Neurological & $93(8.9)$ \\
\hline Diabetes & $123(11.8)$ \\
\hline Neoplasia & $42(4)$ \\
\hline Other & $263(25.2)$ \\
\hline ASA Score, $\mathbf{n}(\%)$ & $438(42)$ \\
\hline ASA Score I & $22(2.1)$ \\
\hline ASA Score II & 0 \\
\hline ASA Score III & \\
\hline ASA Score IV & $(30.4)$ \\
\hline ASA Score V & \\
\hline
\end{tabular}

SD, standard deviation; ASA, American Society for Anaesthesiology

The median procedure duration was 20 minutes (1-120). Procedural duration was significantly longer in procedures that required anesthesiologist-administered sedation (19 vs. 24 minutes, $p=0.001$, Mann Whitney $\mathrm{U}$ test).
Table 2

Procedure data

\begin{tabular}{|l|l|}
\hline \multicolumn{2}{|l|}{ Type of endoscopic procedure, $\mathbf{n}(\%)$} \\
\hline Gastroscopy & $226(21.7)$ \\
\hline Colonoscopy & $429(41.1)$ \\
\hline EUS & $25(2.4)$ \\
\hline ERCP & $329(31.5)$ \\
\hline Small bowel endoscopy & $3(0.3)$ \\
\hline Other * & $31(3)$ \\
\hline
\end{tabular}

Setting of the procedure, $n(\%)$

\begin{tabular}{|l|l|}
\hline Elective procedure & $965(92.5)$ \\
\hline Urgent procedure & $56(5.4)$ \\
\hline Missing data & $22(2.1)$ \\
\hline
\end{tabular}

Indication of procedure, $n(\%)$

\begin{tabular}{|l|l|}
\hline Diagnostic procedure & $363(34.8)$ \\
\hline Therapeutic procedure & $469(45)$ \\
\hline Missing data & $211(20.2)$ \\
\hline Procedure duration, n (\%) & $119(11.4)$ \\
\hline Under 10 minutes & $428(41)$ \\
\hline Between 10-30 minutes & $192(18.4)$ \\
\hline Between 30-60 minutes & $31(3)$ \\
\hline Over 60 minutes & $273(26.2)$ \\
\hline Missing data &
\end{tabular}

EUS, endoscopic ultrasound; ERCP, endoscopic retrograde cholangiopancreatography; *- PEG tube, stricture dilation, esophageal or colonic stenting, balloon dilation of achalasia, etc.

Sedation regimens were highly variable across the 8 participating units. Propofol was used in a majority $(\mathrm{n}=798,76.5 \%)$ of cases, and was administered as the only sedation agent in 240 (23\%) cases. Benzodiazepines (midazolam) were administered in $780(74.8 \%)$ cases, either alone or 
in combination with an opioid (fentanyl) $(\mathrm{n}=232$, $22.2 \%$ ) or propofol $(n=548,52.5 \%)$. Fentanyl was administered exclusively in the setting of anesthesiologist-guided sedation, while propofol and midazolam were widely administered by both endoscopists and anesthesiologists, with variable and heterogenous regimens across centers. In this study $287(27.5 \%)$ procedures were performed under moderate(conscious) sedation, the remaining cases requiring deep sedation (753 cases, $72.2 \%$ ) or general anesthesia ( 3 cases, $0.3 \%$ ).

The impact of sedation on the procedure was assessed by the attending endoscopist and sedation was considered adequate in 986 (94.6\%) cases. Inadequate sedation prolonging or encumbering the procedure was reported in 47 cases $(4.4 \%)$ and was responsible for the premature suspension of the procedure in 10 cases (1\%) cases. These events were more frequent when a non-anesthesiologist was responsible of sedation ( $\mathrm{p}=0.004$ Chi-square test).

In $49(4.7 \%)$ cases, the attending endoscopist reported at least one procedure-related adverse event, of which $9(0.9 \%)$ were endoscopy-related and $40(3.8 \%)$ were anaesthesia-related. Most of these AEs were graded as mild $(n=34,3.3 \%)$ or moderate $(n=14,1.3 \%)$; there was only 1 case of severe $\mathrm{AE}(0.1 \%)$. The most frequently reported anaesthesia-related adverse events were transient hypoxemia $(\mathrm{n}=22,2.1 \%)$ and paradoxical agitation $(\mathrm{n}=10,1 \%)$. The severe adverse event consisted of clinically significant cardiac arrhythmia occurring in a high-risk patient (elderly patient, with an ASA score of IV, undergoing an urgent therapeutic procedure), which required interruption of the procedure, intubation and ICU admission. There were no short-term procedure-related deaths reported in our cohort.
There were 7 cases of mild endoscopy-related complications: 6 cases of post-procedural bleeding $(0.6 \%)$ and 1 case of cholangitis $(0.1 \%)$. In 2 cases, the complications were moderate and consisted of perforation $(0.2 \%)$. None of the patients required surgery or were admitted to the ICU.

There were more anesthesia-related adverse events (ARAE) for complex procedures such as EUS and ERCP (25 events), compared to the other types of endoscopic procedures (15 events) $(p<0.001$, Table 3). Also, there were significantly more anesthesia-related $\mathrm{AE}$ in therapeutic procedures compared to diagnostic procedures $(6.1 \%$ vs $1.9 \%, p=0.002)$. We found no correlation between the rate of anesthesiarelated $\mathrm{AE}$ and the setting of the procedure (emergency vs elective, $p=0.71$ ) or trainee involvement $(p=0.18)$. Also, the ARAE rate did not differ significantly between procedures with anaesthesiologist-guided sedation and those with endoscopist-guided sedation $(3.3 \%$ vs. $4.4 \%$, $p=0.42$ ).

On multivariable analysis, we found that male gender, procedure type (EUS and ERCP) and deep sedation were risk factors for ARAE (Table 3). The risk of ARAE of complex procedures was 37.5 and 5.4 times higher for EUS and ERCP, respectively, than the risk for upper gastrointestinal endoscopy. Deep sedation was found to present an increased risk for ARAEs in our study.There was no association between the sedation regimen and personnel delivering the sedation and increased risk of ARAE. Other patient-related factors (age, ASA status), type of endoscopy center and gastroenterologis-guided sedation, were not associated with an increased risk for ARAE.

\section{Table 3}

Multivariable analysis of potential risk factors for anaesthesia related adverse events

\begin{tabular}{|l|l|l|}
\hline Variable & OR & \multicolumn{1}{l|}{ 95\% C.I } \\
\hline Center (OR compared to center 1) & $(0.0)$ \\
\hline Center 2 & 0.000 & $(0.065-8.158)$ \\
\hline Center 3 & 0.727 & $(0.271-4.378)$ \\
\hline Center 4 & 1.089 & $(0.0)$ \\
\hline Center 5 & 0.000 & $(4.187-705.984)$ \\
\hline Center 6* & 54.372 & $(0,0)$ \\
\hline Center 7 & 0.000 & $(0.189-0.942)$ \\
\hline Female gender* & 0.422 & $(0.980-1.055)$ \\
\hline Age & 1.017 & \\
\hline Procedure (OR compared to upper GI endoscopy) & $(0.703,14.791)$ \\
\hline Colonoscopy & 3.225 & $(5.408-260.408)$ \\
\hline EUS* & 37.526 &
\end{tabular}




\begin{tabular}{|l|l|}
\begin{tabular}{|l|l|l|}
\hline ERCP* & Table 3 (continued) \\
\hline Small bowel endoscopy & 5.421 & $(1.291-22.772)$ \\
\hline Other & 0.000 & $(0.0)$ \\
\hline ASA score (OR compared to ASA score I) & $(0.272,52.828)$ \\
\hline II & 3.791 & $(0.127,1.115)$ \\
\hline III & 0.376 & $(0.142,2.396)$ \\
\hline IV & 0.583 & $(0.278-53.696)$ \\
\hline Responsible of sedation (OR compared to gastroenterologist) \\
\hline Anesthesiologist & 3.867 & $(0.048-0.477)$ \\
\hline Sedation regimen (OR compared to deep sedation) \\
\hline Conscious sedation* & 0.151 & $(0.048-0.477)$ \\
\hline Type of procedure (OR compared to elective procedures) \\
\hline Urgent & 0.263 & $(0.003-2.28)$ \\
\hline
\end{tabular}
\end{tabular}

\section{DISCUSSION}

Sedation is a central issue in modern gastrointestinal endoscopy, as it has been shown to improve tolerance and acceptance of the procedure [8]. However, sedation is not without associated risks and has been shown to account for up to 50\% of adverse events in the endoscopy suite [9].

The results of our study show a wide variability of sedation practices in Romania, both in terms of drug regimens and the staff responsible for sedation. We found a very low incidence of sedation or procedurerelated adverse events in our cohort $(<5 \%)$, irrespective of sedation regimen, highlighting the safety of sedation practices in the endoscopy suite. This, in part, might be attributed to a lower mean age of study population, as higher complication rates for both gastrointestinal endoscopy and anaesthesia are reported for elderly patients [10].

Despite limited available data on use of sedation in gastrointestinal endoscopy in Romania, our findings seem to reflect a significant shift in the practice of endoscopy compared to earlier reports [11]. Sporea et al. reported in 2004 that in all colonoscopies requiring sedation, propofol was preferred in 1329/10083 of procedures (13\%) and the anesthesiologist was responsible of sedation in $100 \%$ of cases. In our analysis, propofol was used in 265/429 (61\%) colonoscopies, and the gastroenterologist was responsible for sedation in $71 / 265(26 \%)$ of cases.

The lack of standardization between endoscopy units regarding the type of sedation administered and personnel responsible for sedation is a problem acknowledged and addressed in other countries as well $[12,13]$. While countries such as Germany and the USA allow endoscopists or registered nurses to guide sedation, most national legislations are either unclear on this point or explicitly enforce deep sedation as the preserve of anaesthesiologists.
Because of the lack of clear guidelines for sedation in gastrointestinal endoscopy in Romania, each participating center was responsible for the sedation regimens used.

In this study we found that propofol was used in the majority of cases $(74.8 \%)$ either alone or in combination with other agents and we found no significant differences in the rate of ARAE between different sedation regimens. An interesting finding was the fact that propofol was usually employed in combination with other drugs, with only $23 \%$ of cases receiving propofol monotherapy, despite the fact that sedation with propofol alone has been shown to be superior to combined regimens [14] and is now preferred by most guidelines except in some particular situations [15]. This also can be explained by the lack of national guidelines and the high variability in sedation practices between centers in Romania, and should be further audited in additional studies.

In 246/753 cases, deep sedation was provided by the attending endoscopist. The practice of endoscopist-delivered deep sedation was, however, very heterogeneous across centers, ranging from $0 \%$ to $100 \%$. Of note, inadequate sedation negatively impacting the technical outcome of the procedure was more likely in case of nonanesthesiology directed sedation ( $\mathrm{p}=0.004)$.

Conscious sedation using benzodiazepines and opioids seems to have a comparable safety profile to that of Propofol administration [16]. A recent metaanalysis of 27 studies showed that anesthesia-related risk is similar between propofol and benzodiazepineopioid combinations regarding moderate adverse effects, such as transient hypoxia (OR 0.82) and transient hypotension (OR, 0.92) [17].

As the number of endoscopic procedures is constantly rising and there is a worldwide workforce shortage of anesthesiologists [18], the task of sedation was to some extent passed on to 
the endoscopist $[1,2,3]$, even if this practice is not always substantiated by national policies. Nonanesthesiologist administered sedation is attractive from a cost and practitioner availability point of view. There are several studies that reported good tolerance to non-anesthesia personnel administered sedation $[19,20]$ but, in most studies, this applied only to low-risk patients (ASA scores I-III)[5]. In our study, the attending endoscopist provided moderate(conscious) or deep sedation in 476 cases, $98.3 \%$ of which for low-risk patients. In high-risk patients (ASA score IV-V) deep sedation was provided exclusively by anesthesiologists.

Despite promising results of non anesthesiologist administered propofol (NAAP), the American Society of Anesthesiology is officially opposed to this practice [21], the major concerns referring to patient safety and proper training. On the other hand, NAAP in endoscopic practice in USA is offered by Registred Nurses or endoscopists in many cases [3].

In countries where the legislation allows it, many endoscopists have grown comfortable with administering routine sedation up to a moderate level and this has been shown to be safe, even in high-risk patients (ASA classes III and IV) [22]. The low overall sedation-related adverse events rate $(3.8 \%)$ in our study also supports this view, although the study was not adequately powered to compare such small differences in ARAE rates as were shown between the anesthesiology and nonanesthesiology directed sedation groups (3.3\% vs. $4.4 \%)$. Such an analysis would have required a significantly larger cohort ( $>10,000$ procedures) and its clinical significance would have been questionable since, as shown in our study, the vast majority of $\mathrm{AE}$ were not severe and did not require any specific intervention. However, in order to ensure safe sedation practices, endoscopy personnel should receive proper training in administering sedation medication which should include skills in recognizing deep levels of sedation and possible complications as well as in the ability to rescue patients when this occurs [3].

We identified some risk factors for ARAE during gastrointestinal endoscopy including the type of procedure(EUS and ERCP), as well as the use of deep sedation, when compared to moderate (conscious) sedation. Although sedation during endoscopy is considered generally safe, deep sedation can impair respiratory functions, whereas conscious sedation does not alter the patient's ability to maintain a patent airway and spontaneous ventilation [6]. Behrens et al. [23], demonstrated an increased risk of sedation related adverse events for ERCP as well as emergency gastroscopies and enteroscopies, compared to diagnostic colonoscopies and EUS. Contrary to available data from the literature [24,25], we reported no increased risk of sedation associated adverse events in the setting of emergency procedures.

Interestingly, according to our results, on multivariate analysis, ASA physical status did not influence the adverse events rate. Some previously reported risk factors are patient-related, such as older age and ASA IV/V status, and some are associated with case complexity, including the use of general anesthesia and longer duration of anesthesia [26]. In our study, procedure type (EUS and ERCP) and male gender were identified as risk factors for sedation-related complications. Interestingly, deep sedation was also shown to be an independent factor for adverse events. Because of the heterogeneous nature of the sedation regimens involved, the study is not adequately powered to allow a more in-depth analysis of this finding, and this should be further explored in subsequent studies.

One of the main limitations of our study is that no systematic documentation of delayed adverse events was performed. However, although some delayed endoscopy-related complications might have been missed, we believe that our protocol was adequately designed to capture the essential safety data pertaining to ARAE, which usually occur either during the procedure or shortly after the procedure was concluded. Taking into account the fact that most sedation protocols were based on short-acting drugs such as propofol and midazolam and the low percentage of procedures requiring general anesthesia $(0.3 \%)$, we consider it highly unlikely that delayed sedation-AE could occur after the 24 hours interval specified in our protocol. Data regarding procedures without sedation were not registered to account for the number of sedated and unsedated procedure in each center, and this information could have been helpful for the general overview of sedation practices in Romania.

While the overall ARAE rate was low, our data suggests that the use of anesthesiologistadministered sedation should be considered for high-risk procedures performed on high-risk patients (i.e. ASA>3) and that GI-directed sedation might be equally safe and could be more cost-efficient [27] for the majority of procedures performed in our daily practice. 


\section{CONCLUSIONS}

The most important conclusion of our study is that sedation in gastrointestinal endoscopy is generally safe, despite a high variability in sedation practices between centers in Romania. However, developing and implementing national guidelines for sedation during gastrointestinal endoscopy is a necessity if we aim to improve the quality of patient care in the endoscopy suite.

Introducere. Asigurarea unei sedări adecvate este necesară pentru efectuarea unui examen endoscopic de calitate. În România, lipsa protocoalelor specifice privind administrarea sedării în endoscopie duce la o variabilitate a acestor practici la nivel național. Acest studiu îşi propune să evalueze practicile curente și siguranța administrării sedării în endoscopie în România, precum și impactul acesteia asupra ratei de succes procedurale.

Materiale și metode. Am efectuat un studiu prospectiv, multicentric, observaţional în care au fost incluși pacienți care au necesitat intervenții endoscopice cu grad variat de sedare. Datele referitoare la statusul pacientului (vârstă, sex, scor AŞA), tipul procedurii, tipul și gradul de sedare, personalul responsabil de administrarea sedării și rezultatele procedurii au fost colectate și analizate. Am evaluat rata efectelor adverse apărute în urma procedurii sau regimului de sedare și impactul sedării asupra procedurii endoscopice.

Rezultate. In analiza finală au fost incluse 1043 de rapoarte endoscopice. In $566(54 \%)$ din proceduri, sedarea a fost asigurată de către anestezist. Regimurile de sedare folosite au variat în funcţie de centru și de experiența locală. Efecte adverse asociate sedării au fost raportate în 40 (3,8\%) din cazuri, fiind minore și reversibile spontan. In urma analizei multivariate $s$-a constatat o asociere între sexul masculin, tipul procedurii endoscopice (ecoendoscopie şi colangiopancreatografie retrograd endoscopică) și sedarea moderată și un risc crescut de complicații periprocedurale.

Concluzii. Sedarea în endoscopie este o procedură cu profil de siguranță bun, în ciuda practicilor variabile pe teritoriul României, însă considerăm necesară elaborarea unor ghiduri naţionale pentru uniformizarea practicii sedării.

Correspondence to : Theodor Voisou, M.D., Ph.D, Gastroenterology Department, Colentina Clinical Hospital, 19-21 Stefan cel Mare Boulevard, Bucharest, Romania, e-mail: theodor.voiosu@gmail.com, fax +40-21-3180604

Acknowledgements: The authors would like to acknowledge all participating personnel involved in the endoscopic procedures.

Conflict of interest disclosure: The authors declare that there are no conflicts of interest.

\section{REFERENCES}

1. FERREIRA A., CRAVO M., SEDATION IN GASTROINTESTINAL ENDOSCOPY: WHERE ARE WE AT IN 2014?. WORLD J GASTROINTEST ENDOSC. 2015;7(2):102-109.

2. GROSS J., BAILEY P., CONNIS R., COTE C., ZUCCARO G., et al., Practice guidelines for sedation and analgesia by non-anesthesiologists. Anesthesiology 2002;96:1004-17.

3. FAIGEL D., BARON T., GOLDSTEIN J., et al., Guidelines for the use of deep sedation and anesthesia for GI endoscopy. Gastrointest Endosc, 2002;56:613-7.

4. SPOREA $\quad$ I., POPESCU A., SANDESC $\quad$ D., BEDREAG $\quad$ O., ASAI $\quad$ R., SIRLI $\quad$ R., ET AL., COLONOSCOPY AND SEDATION IN ROMANIA: EARLY EXPERIENCE USING A BALANCED PROPOFOL REGIMEN. J GASTROINTESTIN LIVER DIS. 2010;19(1):27-3.

5. BATAGA S., TANŢĂU M., CRISTIAN G., STANCIU $\quad$ C., CONSTANTINESCU G., MULDER CJ., $\quad E T \quad A L$. , ERCP IN ROMANIA IN 2006; A NATIONAL PROGRAMME SEEMS MANDATORY. J GASTROINTEST LIVER DIS. 2007;16(4):431-5. 
6. HINKELBEIN J., LAMPERTI M., AKESON J. et al., European Society of Anaesthesiology and European Board of Anaesthesiology guidelines for procedural sedation and analgesia in adults. Eur J Anaesthesiol 2017;34:1-19.

7. EARLY D., LIGHTDALE J., VARGO J., ACOSTA R., DEWITT J., et al., Guidelines for sedation and anesthesia in GI endoscopy. Gastrointest Endosc. 2018 Feb;87(2):327-337.

8. BELL G.,Preparation, premedication, and surveillance. Endoscopy 2004;36:23-31

9. LAZZARONI M., BIANCHI-PORRO G., Preparation, premedication, and surveillance. Endoscopy 2005;37:101-109.

10. MIYANAGA R., HOSOE N., NAGANUMA M.,HIRATA K., FUKUHARA S., KANAI T., et al., Complications and outcomes of routine endoscopy in the very elderly. Endosc Int Open 2018;6(2):E224-E229.

11. SPOREA I., POPESCU A., SANDESC D., et al.,Sedation during colonoscopy. Rom J Gastroenterol 2005;14:195-198.

12. LADAS S., SATAKE Y., MOSTAFA I., MORSE J., Sedation practices for gastrointestinal endoscopy in Europe, North America, Asia, Africa and Australia. Digestion. 2010;82:74-6.

13. VAESSEN H., KNAPE J., Considerable variability of procedural sedation and analgesia practices for gastrointestinal endoscopic procedures in Europe. Clin Endosc 2016;49:47-55.

14. LEE T., LEE C., PARK S., et al., Balanced propofol sedation versus propofol monosedation in therapeutic pancreaticobiliary endoscopic procedures. Dig Dis Sci. 2012;57(8):2113-21.

15. DUMONCEAU J., RIPHAUS A., SCHREIBER F., VILMANN P., BEILENHOFF U., PASPATIS G., et al., Non-anesthesiologist administration of propofol for gastrointestinal endoscopy. Endoscopy. 2015 Dec;47(12):1175-89.

16. MCQUAID K., LAINE L., A systematic review and meta-analysis of randomized, controlled trials of moderate sedation for routine endoscopic procedures. Gastrointest Endosc 2008;67:910-923.

17. WADHWA V., ISSA D., GARG S., LOPEZ R., SANAKA M., VARGO J., Similar risk of cardiopulmonary adverse events between propofol and traditional anesthesia for gastrointestinal endoscopy: a systematic review and meta-analysis. Clin Gastroenterol Hepatol 2017; 15:194-206.

18. DUBOWITZ G., DETLEFS S., MCQUEEN K., Global anesthesia workforce crisis: a preliminary survey revealing shortages contributing to undesirable outcomes and unsafe practices. World journal of surgery 2010 34:438-44.

19. GOUDRA B., SINGH P., GOUDA G., et al., Safety of nonanesthesia provider administered propofol (NAAP) sedation in advanced gastrointestinal endoscopic procedures: comparative meta-analysis of pooled results. Dig Dis Sci 2015; 60:2612-2627.

20. JENSEN J., HORNSLET P., KONGE L., et al., High efficacy with deep nurseadministered propofol sedation for advanced gastroenterologic endoscopic procedures. Endosc Int Open 2016; 4:E107-E111.

21. PEREL A., Non-anaesthesiologists should not be allowed to administer propofol for procedural sedation. European Journal of Anaesthesiology, 2011, 28(8):580-584.

22. LUDWIG T., SCHNIEPER P., DREWE J., PFLIMLIN E., BEGLINGER C., Safety of propofol for conscious sedation during endoscopic procedures in high-risk patients-a prospective, controlled study. The American Journal of Gastroenterology, 2003; 98(8):1751-1757.

23. BEHRENS A., KREUZMAYR A., MANNER H., ELL C., et al., Acute sedationassociated complications in GI endoscopy (ProSed 2 Study): results from the prospective multicentre electronic registry of sedation-associated complications. Gut 2018; 68(3):445-452.

24. FRIELING T., HEISE J., KREYSEL C., et al., Sedation-associated complications in endoscopy - prospective multicentre survey of 191142 patients. Z Gastroenterol 2013;51:568-572.

25. BEHRENS A., LABENZ J., SCHULER A., et al., How safe is sedation in gastrointestinal endoscopy? A multicentre analysis of 388,404 endoscopies and analysis of data from prospective registries of complications managed by members of the working group of leading hospital gastroenterologists (ALGK). Z Gastroenterol 2013;51:432-6.

26. LIEBER S., HELLER B., MARTIN C., HOWARD C., CROCKETT S., Complications of anesthesia services in gastrointestinal endoscopic procedures Clin Gastroenterol Hepatol. 2020;18(9):2118-2127.

27. HASSAN C., REX D., COOPER G., BENAMOUZIG R., Endoscopist-directed propofol administration versus anesthesiologist assistance for colorectal cancer screening: a cost-effectiveness analysis. Endoscopy. 2012;44(5):456-64.

Received $31^{\text {st }}$ January 2021 